\title{
In this issue...
}

Every moment, there is an incremental addition to the knowledge base of any science. This issue of Journal of Horticultural Science hosts the reports on recent developments in different branches of Horticultural Science viz. crop production, crop improvement, crop protection and crop utilization.

A review on innovations in value chain management of tropical fruits by Oberoi and Dinesh summarises the recent developments in the post-harvest processing of tropical fruits. It emphasizes the importance of Farmer Producer Organizations, Good Agricultural Practices, modified atmosphere packaging facilities, controlled atmosphere storage facilities and use of refrigerated containers during transport. Another review article is on importance of $\mathrm{Zn}$ in horticultural crops and status of Zn in soils of Karnataka, India written by Ganesham urthy et al. Besides enumerating the factors affecting Zn availability, it describes how horticultural crops respond to Zn.

There are seven Original Research Papers and Four Short Communications in this issue. Dinesh et al. report a new mango variety with unique characters, "Varate Giduga" that has many characters contributing to deliciousness. Fruits have thick rough and the fruit can be cut into two halves and pulp can be scooped out easily. Merin et al. report on the best suitable timing for crossing in yard long bean. Safeena et al. have evaluated and identified the tuberose cultivars suitable for humid agro-climatic conditions. Meena et al. screened coriander varieties for their resistance to aphids and identified least susceptible varieties. Mini Shankar et al. identified the ferns species suitable for landscape purpose.

With respect to production aspects, Linta Vincent et al. identified the leaf parameters and their correlation to resistance to PRSV in wild relatives of papaya. Satisha and Somkuwar report the effect of leaf removal on composition of grape varieties grown in India. Ganeshamurthy et al report the Compositional Nutrient Diagnosis (CND) norms for potato that would help in hidden hunger of various nutrients and their management in potato. Manisha and Priya Devi report on the significant effect of calcium ions over potassium ions on papaya seed germination and seedling vigour when salts of these ions are used to prime papaya seeds. A short communication by Chitra, describes the superiority of use of tissue culture derived planting material of turmeric over the conventional rhizomes. Disease free planting material production can be facilitated by tissue culture in turmeric.

The biotic stress management is ever demanding aspect. Jayanthi Mala et al. report the management of Jamun seed borer (Anselmella kerrichi) using spinosad. Amrutha and Reshmy report on characterization of Rhizoctonia solani that causes fruit rot in strawbeery and its management using Trichoderma asperellum and Pseudomonas fluorescens.

The new editorial team has tried to stand up to the expectations of the community of Horticultural Scientists and students. There is scope for improvement and the team will keep efforts to improve the standard of the Journal.

The Editorial Team gratefully acknowledges the reviewers who have contributed immensely for the better presentation of the journal.

Wishing you a very happy and scientifically productive new year 2020.

S. Sriram

Editor in Chief 